\title{
Tijdschrift Sociologie
}

Tijdschrift Sociologie 1: 67-74

(c) de auteur(s) 2020 (c) CC BY NC ND 4.0 () (c) (7)

https://doi.org/10.38139/TS.2020.10

http://www.tijdschriftsociologie.eu

\section{Essay \\ Als in een film: waarom een wereld in crisis soms niet helemaal echt lijkt}

\section{Kobe De Keere}

Universiteit van Amsterdam

k.dekeere@uva.nl
'Het lijkt wel alsof we in een film gevangen zitten' hoor ik vaak wanneer mensen me probeerden uit te leggen hoe ze zich voelden tijdens de eerste weken van quarantaine. De shock van de genomen maatregelen en het dreigende gevaar van een virus waar we moeilijk vat op lijken te krijgen, kwam (of komt nog steeds) zo schrikbarend en vreemd over dat het ook in onze hoofden nauwelijks leek in te dalen. We kijken ernaar als een film. Een heel spannende film, een thriller, die ons doet huiveren en beven, maar die tegelijkertijd ook niet helemaal echt lijkt. De filmpas Cineville maakte zelfs gebruik van deze onwezenlijke ervaring in hun nieuwe reclamecampagne voor online films kijken: 'De komende tijd blijven we thuis voor elkaar. Daarom sloten filmtheaters hun deuren en zijn de straten leeg. We vinden dat maar een raar beeld. Bijna alsof we zelf in een film terecht zijn gekomen.' Maar waarom precies? 


\section{Massamedia of psychologie?}

Er zijn verschillende plausibele verklaringen mogelijk voor deze filmische ervaring. Cultuurcritici zoals Theodor Adorno (2001), Guy Debord (1967) of Jean Baudrillard (1981) hebben, elk op hun manier, reeds benadrukt hoe massamedia en popcultuur in toenemende mate onze werkelijkheid is gaan vervormen. Ons dagelijks leven is zo gekoloniseerd geraakt door hyperreële en artificiële beelden dat het onze verlangens en denkkaders is gaan vormen. Het onderscheid tussen fictie en non-fictie is zo vervaagd dat ook de huidige situatie het makkelijkst gelezen kan worden door een hollywoodiaanse lens. Levensgevaarlijke virussen en dokters in beschermende pakken kennen we dan ook vooral van series en films. Toch is een dergelijke verklaring niet helemaal bevredigend. Het onderschat in de eerste plaats de impact van de echt beleefde en tactiele wereld (onze zintuigelijke ervaringen gaan een stuk verder dan enkel het audiovisuele). En daarnaast hebben de lockdownervaringen vandaag ook niet zo heel veel gemeen met die van een spannende film. De meeste van ons zitten vooral thuis op de bank, proberen kinderen bij te scholen, hebben ongemakkelijke videogesprekken met vrienden of zijn bezorgd om oudere familieleden. Fijn is het zeker niet maar ook niet meteen materiaal voor een meeslepende blockbuster.

Er is ook een meer psychologische verklaring mogelijk. De ervaring afstand te nemen van onze eigen werkelijkheid wordt door psychologen ook weleens derealisatie of disassociatie genoemd en is een vrij goed gedocumenteerd cognitief verschijnsel. Volgens de DSM (de diagnostieke bijbel van therapeuten) gaat het over een psychologische staat waarbij we onze ervaringen, van ons eigen lichaam of zelfs de hele wereld rondom ons, lijken los te koppelen van ons eigen ik. Hierdoor gaat alles vreemd en onecht aanvoelen. Het staat niet helemaal vast waarom dit soms gebeurt maar er lijkt een sterk verband te bestaan met stress, onzekerheid en angst. Alsof we, door tijdelijk de wereld even weg te duwen, onszelf kunnen beschermen voor de ergste impact en op die manier het verwerken van een trauma bewaren voor een later en veiliger moment.

Deze bijna filmische ervaring die velen van ons de eerste weken ervaarden, zouden we mogelijk kunnen interpreteren als een collectieve staat van derealisatie. We proberen de enge werkelijkheid voor een stukje van ons af te duwen om op die manier niet overmand te raken door angst of paniek. En het is zeker niet uit te sluiten dat dit psychologisch mechanisme een rol speelt bij de individuele ervaring van sommigen. Toch is het niet helemaal een afdoende verklaring voor het collectieve onwerkelijkheidsgevoel die de COVID-19-situatie nu bij ons oproept. Hoewel het verplicht thuiszitten voor heel wat mensen tot traumatische ervaringen kan leiden (denk maar aan de toename van huiselijk geweld of de mentale problemen die ontstaan door langdurige isolatie), is het misschien wat kort door de bocht om dit te zien als de verklaring voor het vrij abrupte gevoel van ontheemding dat al ontstond op dag één van de maatregelen. De dreiging zit voor de meeste onder ons voorlopig nog wat gevangen op een abstract niveau en zal zich pas over een langere tijd echt gaan manifesteren. Daarbij is het altijd lastig om individueel psychologisch mecha- 
nismen simpelweg te extrapoleren als verklaring voor bredere maatschappelijke fenomenen.

\section{De sociale constructie van de werkelijkheid}

Er is een andere en net zo belangrijke reden waarom we het gevoel hebben filmpersonages te zijn in een apocalyptische film (maar dan zonder Bruce Willis of Will Smith). Die heeft minder te maken met psychologische mechanismen zoals angstreductie of associaties met bestaande filmscenes, maar met de sociale fundamenten van onze werkelijkheid. In de eerste plaats worden onze dagelijkse routines stevig ontregeld en dat heeft een grotere impact dan we misschien aanvankelijk denken. Laten we daarom eens teruggrijpen naar een aantal ideeën uit het klassieke boek van Peter Berger en Thomas Luckman met de iconische titel The Social Construction of Reality (1966). Hun logica laat ons toe onze ervaringen anders te kaderen en misschien zelfs te anticiperen op de toekomst.

De kern van hun argument is dat de realiteit waarin we leven altijd een gedeelde realiteit is. De werkelijkheid, zoals we die elke dag ervaren en waaraan we nooit helemaal kunnen ontsnappen, is geen a priori-gegeven maar wordt ons altijd door anderen aangereikt. En, zo stellen Berger en Luckman, die realiteit mag dan wel vanzelfsprekend aanvoelen, dat betekent absoluut niet dat deze zich zomaar komt aandienen. Er is best wel veel sociale arbeid nodig om onze gedeelde werkelijkheid tot stand te laten komen en te onderhouden. Hun vraag was dus niet welke werkelijkheid echt is, maar hoe we een werkelijkheid aanvaarden die we eigenlijk van anderen overnemen.

Hun antwoord op deze vraag ligt in de eerste plaats in routine en herhaling. Onze realiteit is altijd een work-in-progress, altijd under construction. Elke dag opnieuw voeren we interacties op dezelfde manier uit, bevestigen we rolpatronen en bestendigen we denkkaders. Als we bepaalde handelingen, ideeën of interacties maar lang en vaak genoeg herhalen, veranderen ze langzaam in codes en conventies of uiteindelijk zelfs in zelfstandige instituten. Dan zijn ze met andere woorden zo verhard dat ze bijna als a-sociaal en a-historisch gaan aanvoelen. Het meest frappante voorbeeld hiervan is waarschijnlijk de sociale constructie van geld. Munstukken, bankbiljetten of cijfertjes op je bankrekening hebben geen intrinsieke waarde, maar door een lang proces van herhaling, is geld uiteindelijk zo gelegitimeerd geraakt dat we de sociale oorsprong ervan vergeten zijn. Geld lijkt nu gewoon objectief te bestaan en de reden hiervoor is dat we, door elke dag opnieuw met geld te betalen, het continu herbevestigen als een realiteit. Elke keer dat de pinpas wordt uitgehaald, legitimeren en bestendigen we dus - vaak met miljoenen tegelijkertijd - de werkelijkheid van geld.

Echter gaat dit proces van constante creatie van de realiteit niet enkel op voor geld, maar voor nagenoeg onze hele leefwereld. Door het doorlopend herhalen van sociale handelingen en conventies - van je buurvrouw goeiedag zeggen tot het beta- 
len van je belastingen - creëren we samen een werkelijkheid die tegelijkertijd objectief feitelijk aanvoelt en toch ook subjectief betekenisvol. Dit lijkt nu allemaal nogal voor de hand liggend en weinig verontrustend. Het wordt echter wel lastig wanneer we als samenleving geconfronteerd worden met een situatie die deze dagelijkse patronen en routines ernstig verstoren.

\section{Rustige en roerige tijden}

Wanneer we nu collectief in een situatie terecht komen die ons belemmert om de routine van ons sociaal handelen te handhaven, dan moeten we niet alleen een oplossing zoeken in andersoortig gedrag maar tast het onvermijdelijk ook een deel van onze werkelijkheid aan. Ann Swidler (1986), een gerenommeerd cultuursocioloog van de Universiteit van Californië in Berkeley, stelt dan ook dat de culturele instrumenten die we hebben om de leefwereld te interpreteren en er ons in te navigeren heel anders werken afhankelijk van hoe stabiel deze wereld is. In zogenaamde settled times (rustige periodes) hoeven we eigenlijk vrij weinig te doen om onze realiteit toch als vanzelfsprekend te ervaren. We kunnen terugvallen op dagelijkse kennis en gedragspatronen die we van jongs af aan zijn gaan belichamen. Een beetje 'gezond verstand' - of 'common sense' zoals Swidler het noemt - brengt je dan al een heel eind. Echter in unsettled times (roerige periodes) werken die onbewuste denkbeelden minder goed en moeten we dieper gaan graven in onze culture gereedschapskist om vat krijgen op onze omgeving.

Het is zeker zo dat populaire cultuur, zoals films, een wezenlijk deel uitmaken van onze culturele gereedschapskist. Swidler (2013) zelf onderzocht bijvoorbeeld mooi hoe onze verwachtingen over liefdesrelaties sterk gestuurd worden door een hollywoodiaans idee van romantiek. Dit geldt natuurlijk ook voor hoe we nadenken over armoede (McArthur en Reeves 2019), criminaliteit (Cohen 2002) of zelfs onze eigen psychische gezondheid (Illouz 2008). Dus in dit opzicht is het niet zo heel vreemd dat we initieel terugvallen op cinema-associaties om de nog ongekende pandemische gezondheidscrisis te kaderen. Maar er is meer aan de hand dan enkel associaties.

Waar het op neerkomt is dat in roerige tijden vaste patronen hun betrouwbaarheid verliezen en we daardoor andere en meer reflectieve kennis gaan aanboren om gedachten en gedrag te sturen. We kunnen niet zomaar meer op automatische piloot verdergaan, maar moeten nu in boogjes om elkaar heen wandelen, vrienden anders gaan begroeten en met collega's communiceren via een laptopcamera. Dit betekent bijvoorbeeld dat we affectie op een andere manier moeten tonen (een vlug schouderklopje kan niet meer) en dat gangbare strategieën voor conflictoplossing niet meer ingezet kunnen worden (zullen we even koffie gaan drinken?). Dingen die vroeger gewoon gezond verstand leken en automatisch tot stand kwamen, werken nu soms helemaal niet meer. Met andere woorden, verliest onze hele leefwereld even zijn vanzelfsprekendheid waardoor die ongemakkelijk, vreemd of zelfs onwer- 
kelijk gaat aanvoelen.

De inwoners van de meeste westerse landen hebben, althans relatief gesproken en op collectief niveau, best weinig ervaring met roerige tijden. Onze wereld, inclusief de veiligheid en het comfort die we beleven, voelt vaak nogal vanzelfsprekend aan. De verspreiding van het dodelijke coronavirus heeft daar plots drastische verandering in gebracht. De noodzakelijke maatregelen om het gevaar van het virus in te perken hebben een heel aantal van onze alledaags handelingen stevig in de war gestuurd. We nemen plaats in lege bussen, volgen online les en stappen in de ochtend niet meer in onze auto's om naar het werk te rijden. We leven nog op dezelfde plek, maar als we door het raam kijken lijkt er toch iets niet helemaal te kloppen. We kunnen daar best rationeel over nadenken, maar het blijft een beetje vreemd voelen.

\section{Aftiteling}

Misschien het vervelendste van de film waar we in terecht zijn gekomen, is dat we niet precies weten hoe lang die nog duurt. Wanneer komt eigenlijk de aftiteling? Het handige aan een vanzelfsprekende wereld is dat die altijd maar lijkt door te gaan. We kunnen vandaag dingen ondernemen, plannen of uitstippelen omdat we weten dat morgen grosso modo hetzelfde blijft als vandaag. Dit betekent niet dat we geen trajecten voor onszelf uitstippelen die tot verandering kunnen leiden, maar dit doen we altijd met de veronderstelling dat de meeste van onze conventies blijven gelden. We gaan studeren omdat we ervan uit gaan dat een diploma binnen tien jaar nog net zo legitiem is als vandaag. We kopen een huis omdat we er vanuit gaat dat eigendomsrecht niet zomaar zal verdwijnen. Dus we projecteren dan wel levenspaden naar de toekomst, maar de horizon van mogelijkheden waarbinnen dit gebeurt kan enkel bestaan door een sterk vertrouwen dat alles uiteindelijk altijd maar blijft doorgaan. De huidige pandemie, zo lijkt me, heeft voor velen onder ons dit vertrouwen ernstig aangetast.

Waarschijnlijk heeft het niet veel zin te wachten tot de aftiteling komt om te ontsnappen uit de film. Het klinkt misschien wat ongemakkelijk, maar die oude werkelijkheid komt nooit meer terug. Sommige oude gewoontes zullen zich waarschijnlijk herstellen, maar de abrupte onderbreking zal ook langdurige effecten hebben op zowel macro- (bijvoorbeeld economische groei) als microniveau (bijvoorbeeld ons begrip van veilige en onveilige interacties). Net zoals New York voor New Yorkers nooit meer helemaal hetzelfde voelde na 9/11, zelfs na het herbouwen van WTC-torens. Niet per se omdat we vanaf nu altijd bang zullen zijn van dodelijke virussen (hoewel dit de komende jaren mogelijk vaker aan de orde zal zijn), maar simpelweg omdat een nieuwe werkelijkheid terug opgebouwd zal moeten worden. We zullen opnieuw routines, ritmes en patronen creëren die uiteindelijk weer zullen verharden in codes, tradities en instituten. Het is bijvoorbeeld nog een open vraag of de toegenomen waardering voor gezondheidswerkers en winkelpersoneel zich zal 
vertalen in een nieuwe sociale status, maar de mogelijkheid hiertoe is nu wel gecreëerd. Wel merken we hoe vlug de anderhalvemetereconomie een 'werkelijkheid' lijkt te worden. De film zal dus niet plots aflopen, maar geleidelijk aan terug een realiteit worden. Al wordt het misschien niet de werkelijkheid waar we hoopten in te leven, deze zal wel steeds vertrouwder gaan aanvoelen.

\section{Klaar voor een sequel?}

Er bestaat geen enkele manier om een ramp waarbij duizenden mensen het leven laten en anderen voor het leven getekend zijn door het verlies van een woning, baan of dierbaren als enigszins positief te kaderen. Het is dan ook wat vreemd om te wijzen op de verbeterde luchtkwaliteit, een herstellende biodiversiteit of een dalende $\mathrm{CO} 2$-uitstoot als zouden het voordelen van deze coronacrisis zijn. Dit zijn enkel signalen dat onze manier van leven voordien vernietigend en desastreus was, maar niet dat een pandemie ook haar positieve kanten heeft. Dit betekent echter niet dat er geen lessen te trekken zijn uit onze beleving nu. De deconstructie van onze werkelijkheid is wel een collectieve ervaring die een reset van onze werkelijkheid mogelijk maakt.

Deze reset is ook broodnodig aangezien dat onze vroegere conventies, denkkaders en instituten nog een aantal crisissen in de incubatie hebben gelegd. De wetenschappers van de Bulletin of Atomic Scientists, een panel experts aan de Universiteit van Chicago, plaatste dit jaar hun doomsday clock op honderd seconde voor middernacht. Het dichtste dat de klok, sinds haar start in 1947, ooit bij het finale eindpunt heeft gestaan. Nog los van de huidige pandemie, stelt dit panel dat een combinatie van toenemende nucleaire onzekerheid (aflopen van nucleaire verdragen), geopolitieke spanningen (verschuivende machtsbalansen) en de nakende klimaatcrisis ervoor zorgt dat onze huidige globale samenleving een enorm risico loopt om snel te destabiliseren. En dan hebben we het nog niet over de toenemende ongelijkheid, racisme en nationalisme. Er is geen pasklare formule die ons toelaat het roer drastisch om te gooien, wel kunnen we putten uit onze ervaringen nu om de reconstructie van de werkelijkheid anders aan te pakken.

We leren eigenlijk vandaag dat onze vanzelfsprekende werkelijkheid niet zo noodzakelijk is als we vaak dachten. Dingen kunnen ook echt anders. Dit zou een terugkeer naar het geloof in een maakbare samenleving kunnen inluiden. Een idee dat sterk leefde na de Tweede Wereldoorlog en ontegensprekelijk een rol speelde in het uitbouwen van sterke verzorgingsstaten binnen en buiten Europa. De laatste decennia, daarentegen, werden de vrije markt en liberaal-economische dynamieken zo genaturaliseerd, dat we bijna vergaten dat ook dit economisch systeem - inclusief haar 'regels' en 'wetten' - ook 'slechts' een sociale constructie is. Een discours dat al langer door antikapitalistische sociale bewegingen wordt verkondigd vindt misschien nu meer draagvlak.

Het is echter nog koffiedikkijken of de politiek terug in deze oude gewoontes 
zal vervallen en de samenleving opnieuw een rekening onder de neus gaan duwen. Of dat we nu een andere verhaallijn gaan uitstippelen waarbij collectief welzijn primeert en solidariteit eerder als oplossing dan als probleem wordt gezien. Bovendien creëren nieuwe gedragspatronen en routines andere horizonten van mogelijkheden. Nu meer dan ooit is het de tijd om deze aan een snel tempo te gaan exploreren.

Daarnaast merken we nu goed hoe we in rustige tijden (settled time) eerder onkritisch en weinig beschouwend omspringen met onze culturele denkbeelden. Het grootste risico hiervan is waarschijnlijk dat dit het negeren van problemen eerder aanmoedigt dan het oplossen daarvan. Het onderzoek van de etnograaf Mari Nordgaard (2011) naar hoe inwoners van een Noors skioord reageren op verminderde sneeuwval als een gevolg van de opwarming van de aarde is hier een mooi voorbeeld van. Nordgaard vestigde zich een tijdje in deze gemeenschap om beter te begrijpen hoe haar leden omspringen met het idee dat de economische leefbaarheid van de regio onder druk komt te staan door deze klimaatsverandering. Talloze interviews later moest ze tot de conclusie komen dat culturele gemeenplaatsen die deel uitmaken van het Noorse 'gezond verstand' ('wij, Noren, zijn nu eenmaal gewend om te gaan met een weerbarstige natuur') vooral tot een permanente staat van ontkenning leiden. De inwoners bleven vasthouden aan bestaande patronen en conventies waardoor er nauwelijks ruimte was voor noodzakelijke reflectie over hun onvermijdelijke toekomst. In Nederland is dat natuurlijk nauwelijks anders. Ook in de huidige crisis zorgden Nederlandse denkbeelden ('wij nuchtere Nederlanders raken niet snel in paniek, dus doe maar gewoon') voor een vertraagde reactie op een crisis die al in volle opgang was.

De uitdaging waar we nu voor staan is om in roerige tijden even tegen het licht te houden hoe 'gezond' ons gezond verstand precies is. Dit impliceert, volgens mij, op zijn minst twee dingen. Ten eerste, is dit een moment om te leren uit de fouten van de bewoners van het Noorse skioord en om onze routines en conventies niet toe te laten te verglijden in een ontkenning van nakende crisissen. Als we dan toch een nieuwe realiteit moeten scheppen, dan maar beter een die ons niet verlamt maar voorbereidt op de aankomende uitdagingen. Ten tweede, merken we nu, meer dan ooit tevoren, hoe belangrijk experts en kritische kennis zijn. In rustige tijden komen we best ver met automatische gewoontes en denkkaders waardoor wetenschappelijke kennis soms een overbodig gedoe lijkt. Vandaag leert een wereldwijde crisis ons dat we zonder experts nauwelijks weten hoe we moeten reageren op een dergelijke ramp. Een samenleving zonder kenniselementen die dagelijkse patronen niet alleen onderzoeken maar ook durven te bekritiseren, blijft een fragiele samenleving. Zonder reflectieve kennis zijn we niet klaar voor roerige tijden en kunnen we weinig anders dan voor ons uit staren en zeggen 'het voelt net als in een film'. 


\section{Literatuur}

Adorno, T.W. (2001) The culture industry: Selected essays on mass culture. London: Routledge. Baudrillard, J. (1981) Simulacres et Simulation. Paris: Éditions Galilée.

Berger P.L. en T. Luckmann (1966) The Social Construction of Reality: A Treatise in the Sociology of Knowledge. New York: Anchor Books.

Cohen, S. (2002) Folk devils and moral panics: The creation of the mods and rockers. London: Routledge.

Debord, G. (1967) La Société du spectacle. Paris : Gallimard.

Illouz, E. (2008) Saving the modern soul: Therapy, emotions, and the culture of self-help. Berkley: University of California Press.

McArthur, D. en A. Reeves (2019) The rhetoric of recessions: how British newspapers talk about the poor when unemployment rises, 1896-2000. Sociology, 53(6): 1005-1025.

Norgaard, K.M. (2011) Living in denial: Climate change, emotions, and everyday life. Cambridge: MIT Press.

Swidler, A. (1986) Culture in Action: Symbols and Strategies. American Sociological Review, 51(2): 273-286.

Swidler, A. (2013) Talk of love: How culture matters. Chicago: University of Chicago Press.

\section{Over de auteur}

Kobe De Keere is socioloog aan de Universiteit van Amsterdam. 